\title{
OVICIDAL ACTIVITY OF OILS AGAINST LIGHTBROWN APPLE MOTH (EPIPHYAS POSTVITTANA) ON KIWIFRUIT LEAVES
}

\author{
A.R.TOMKINS and C. THOMSON
}

\author{
Ruakura Agricultural Centre, Private Bag, Hamilton
}

\section{SUMMARY}

Laboratory bioassays were conducted to investigate the ovicidal activity of both natural and petroleum oils against lightbrown apple moth (Epiphyas postvittana (Walker)) on kiwifruit leaves. Eggs were laid onto oil treated leaves or oils were applied to eggs after laying. Strong ovicidal activity was demonstrated for petroleum oils, particularly an intermediate oil. The stage of embryogenesis at which mortality occurred, differed between products. All of the oil products were more effective when applied directly to eggs than when applied to leaves prior to laying. Keywords: lightbrown apple moth, petroleum oil, natural oil, ovicides, kiwifruit

\section{INTRODUCTION}

Both natural and petroleum-based oils have been used to control fruit pests for many years (Smith and Salkeld 1966). Petroleum oils are still commonly used in the United States and Europe as dormant or late dormant applications to control pests overwintering on apple trees. This use includes very effective control of leafroller overwintering as eggs on the branches of apple trees (Chapman et al 1941).

In New Zealand, petroleum oils are used to kill the eggs of some pests (eg. European red mite (Panonychus ulmi Koch) (Collyer and van Geldermalsen 1975)) overwintering on apple trees, but not leafrollers as the species present in this country do not overwinter as diapausing eggs. Some oils are used during the summer, particularly on citrus, when their ovicidal activity could affect leafroller eggs. This use of oils has been avoided on kiwifruit due to phytotoxicity found in early trials (Sale 1972). However, the more recently developed oils including natural oils may be less phytotoxic and safer to use on a wider variety of plants. Naturally derived oils have been demonstrated to have ovicidal activity against lepidopterous pests (Taschenburg 1953) including codling moth (Cydia pomonella L.) (Hough and Jefferson 1936). A recent revival of interest in the development of effective, less phytotoxic oils (Rock and Crabtree 1987) is being fuelled by increasing public concern about pesticide residues on fresh produce.

This paper reports an investigation of the ovicidal activity of three oil-based products against lightbrown apple moth (LBAM) (Epiphyas postvittana (Walker)) egg batches laid on kiwifruit (Actinidia deliciosa var. deliciosa cv. Hayward) leaves. Two of the five types of petroleum oils in use New Zealand were tested. These were an all purpose (Shell Sunspray with viscosity measured in Saybolt universal seconds (SUS) at $37.8^{\circ} \mathrm{C}=75$ ) and an intermediate oil (Mobil 663, SUS $=93$ ). All purpose oils are more highly refined enabling their use on some tree crops (eg. citrus) during summer whereas intermediate oils can only be used on deciduous trees at green-tip. Both of these petroleum oils are paraffinic and used as miticides and/or insecticides. The third oil product, Yates Naturoil, consists of blended vegetable oils and is used as an additive to herbicides. Treatments were applied pre- or post-oviposition, as the time of application relative to oviposition can have a major effect on the level of ovicidal activity of insecticides (McGhie and Tomkins 1988).

\section{METHODS}

LBAM used in these bioassays were obtained from DSIR Rearing Section or a Proc. 45th N.Z. Plant Protection Conf. 1992: 167-170 
Ruakura colony originating from the same source. For oviposition, three or four pairs of 3-day-old LBAM were caged in a gauze bag on the leaf of a potted kiwifruit plant, and allowed to oviposit for up to 3 days. Only eggs less than 3 days old were used to reduce variation in the susceptibility to treatments of different aged batches (McGhie and Tomkins 1988). Treatments were applied pre-oviposition, before LBAM were caged onto each leaf, and post-ovipostion, by dipping leaves in constantly agitated oil suspensions for 30 seconds and then allowing them to dry under ambient conditions. Three rates of each oil treatment were tested (Table 1). Control leaves were dipped in water. Each replicate consisted of a leaf on which an average of 18 egg batches had been laid. The average number of eggs per batch was 26 . Treatments were replicated at least twice, with replicates treated on different days to allow for sufficient moths of similar ages to be used.

After treatment, batches were held under ambient conditions for 7-14 days before microscopic examination to determine the success of eclosion. Two pre-oviposition treatments (all purpose oil at 0.5 and $1.0 \%$ ) were lost when a large proportion of the egg batches were eaten by ants. The stages of development reached by eggs were recorded to assist future studies on the effects of oils on egg parasites (eg. Trichogramma spp.) and interaction of oils with other types of insecticides when used in mixtures. Several stages in the development of both insecticide-treated and control egg batches were recognised. LBAM egg batches were green when freshly laid, gradually becoming yellow before the larval eye spots appeared, with the embryo visible shortly before eclosion. Some treated egg batches became brown and ceased their development, at a time corresponding with the development of eye spots in untreated eggs. Other batches failed between the appearance of the embryo and eclosion. The proportion dying at each stage was recorded. All data were subjected to logit regression analysis.

\section{RESULTS}

In the post-oviposition test, the intermediate oil, had the highest level of ovicidal activity and the natural oil the least (Table 1 ). At the $2 \%$ rate, the proportion of eggs which hatched was significantly lower for the natural oil $(\mathrm{P}<0.05)$, all purpose oil $(\mathrm{P}<0.01)$ and intermediate oil $(\mathrm{P}<0.001)$ treatments compared to the untreated control.

A significant reduction in egg hatch for pre-oviposition application of oils was only recorded for $1.0 \%(\mathrm{P}<0.01)$ and $2 \%(\mathrm{P}<0.001)$ rates of intermediate oil (Table 1). Egg hatch for all three rates of intermediate oil was significantly lower $(\mathrm{P}<0.05)$ when applied post-oviposition compared with pre-oviposition.

TABLE 1: Percent hatch ( \pm se) of lightbrown apple moth eggs laid on kiwifruit leaves and treated with petroleum or vegetable-based oils pre- or post-oviposition.

\begin{tabular}{lccc}
\hline Treatment & Rate $(\%)$ & Pre-oviposition & Post-oviposition \\
\hline Control & & $89.0(7.8)$ & $92.4(9.1)$ \\
Natural oil & 0.5 & $97.7(6.3)$ & $86.1(13.0)$ \\
(Yates Naturoil) & 1.0 & $88.9(7.7)$ & $13.4(18.1)$ \\
& 2.0 & $90.0(7.3)$ & $49.2(19.6)$ \\
All purpose oil & 0.5 & $-*$ & $3.0(12.2)$ \\
(Shell Sunspray) & 1.0 & - & $24.8(20.6)$ \\
& 2.0 & $59.5(34.9)$ & $15.9(20.3)$ \\
Intermediate oil & 0.5 & $62.3(23.1)$ & $19.0(20.0)$ \\
(Mobil 663) & 1.0 & $63.1(12.3)$ & 0 \\
& 2.0 & $33.2(13.6)$ & 0 \\
\hline
\end{tabular}

* - treatments lost

The stages at which eggs failed to continue their development were grouped into two categories; "pre-embryo" representing eggs dying during the green or brown stages 
and "embryo" for eggs that died after the embryo became visible or failing subsequently before eclosion. Significant differences $(\mathrm{P}<0.05)$ were found between treatments applied pre- or post-oviposition in the proportions of the eggs which died in the "preembryo" stage compared to the proportion which died at later stages of development. Figure 1 shows that for eggs treated pre-oviposition with intermediate oil, a greater proportion of eggs which did not hatch, failed at the "pre-embryo" stage than for untreated eggs. Most (99-100\%) of the eggs treated post-oviposition with intermediate oil died during the "pre-embryo" stage.

\section{DISCUSSION}

The mortality of leafroller eggs caused by the two petroleum oils tested was probably related to their viscosity, as previously shown for the ovicidal activity of a wider range of petroleum oils against codling moth (Newcomer and Yothers 1932). Thus, the intermediate oil, which has a higher viscosity had a corresponding higher level of ovicidal activity than the all purpose oil. The viscosity of petroleum oils increases with their molecular weight, which has also been related to their level of ovicidal activity (Fiori et al 1963). These factors determine how long an oil will persist and remain in contact with treated eggs before volatilisation. The shorter persistence of natural oils may explain the lower level of activity found for this product included in our study. It should be noted that increasing the viscosity of oils also raises their phytotoxicity, so that a balance must be found between having sufficient viscosity for pest control while having minimal phytotoxic effects (Chapman et al 1962).

Our study indicates that oils should be applied after leafroller eggs have been laid. Newcomer and Yothers (1932) killed a large proportion (79-94\%) of codling moth eggs laid after applying a viscous oil (SUS $=230$ ), provided oil residues were less than 4 days old. However, when they used an oil with lower viscosity (ie. SUS $=52$ ), differences in the levels of mortality with pre- and post-oviposition applications were similar to those in our study with the intermediate oil.

Insect growth regulators have higher ovicidal activity when applied pre-oviposition (McGhie and Tomkins 1988), the opposite effect of oils, probably due to their different mode of action. The smothering activity of oils (Smith and Salkeld 1966) is favoured by the post-oviposition application whereas pre-oviposition application of insect growth regulators would enable them to affect embryogenesis at an earlier stage. The ovicidal activity of oils and insect growth regulators appears to be complementary and the efficacy of mixtures is currently under evaluation.

While the results of these laboratory studies are encouraging, oils need to be evaluated under field conditions where their ovicidal activity may be less than expected from laboratory tests (Zidan et al 1987).

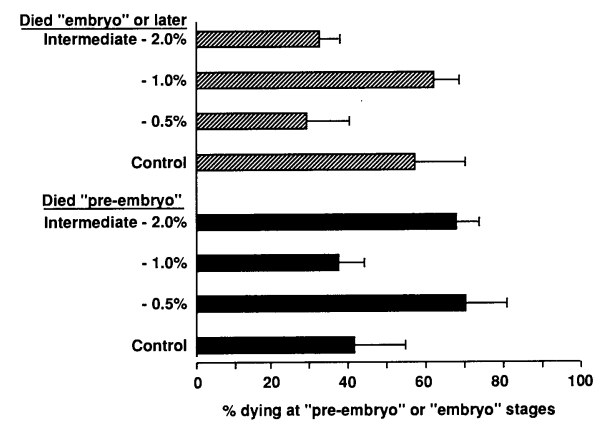

Fig. 1: Proportion of total number of eggs which did not hatch that died before or after appearance of the embryo in lightbrown apple moth (Epiphyas postvittana) egg batches laid on kiwifruit leaves treated with oils causing significant $(\mathbf{P}<0.05)$ mortality when applied pre-oviposition (bars represent standard errors). 
To Ms. B. Dow for statistical analysis.

\section{REFERENCES}

Chapman, P.J., Pearce, G.W. and Avens, A.W., 1941. The use of petroleum oils as insecticides. II. Oil deposit and the control of fruit tree leafroller and other apple pests. J. Econ. Entomol. 34: 639-647.

Chapman, P.J., Lienk, S.E., Avens, A.W. and White, R.W., 1962. Selection of a plant spray oil with minimum plant injury hazards. J. Econ. Entomol. 55: 737-744.

Collyer, E. and van Geldermalsen, M., 1975. Integrated control of apple pests in New Zealand 1. Outline of experiment and general results. N.Z. J. Zool. 2(1): 101134.

Fiori, B.J., Smith, E.H., and Chapman, P.J., 1963. Factors influencing the ovicidal effectiveness of saturated petroleum oils. J. Econ. Entomol. 56: 885-888.

Hough, W.S. and Jefferson, R.N., 1936. Tests of insecticidal efficiency of some contact sprays against codling moth eggs. J. Econ. Entomol. 29: 537-541.

McGhie, R.A. and Tomkins, A.R., 1988. Laboratory evaluations of insect growth regulators against lightbrown apple moth. Proc. 41 st N.Z. Weed and Pest Control Conf.: 243-247.

Newcomer, E.J. and Yothers, M.A., 1932. Experiments with insecticides for codling moth control. U.S.D.A. Bulletin 281. 29p.

Rock, G.C. and Crabtree, K.W., 1987. Biological activity of petroleum and cottonseed oils against two tetranychiid mite species and two tortricid insect species found on apple. J. Agric. Entomol. 4: 247-253.

Sale, P.R., 1972. Oil and Chinese gooseberries do not agree. Orchardist of N.Z. 45:3031.

Smith, E.H. and Salkeld, E.H., 1966. The use and action of ovicides. Ann. Rev. Ent. 11: 331-368.

Taschenberg, E.F., 1953. Evaluation of petroleum and vegetable oils on grape berry moth eggs. J. Econ. Entomol. 46: 85-91.

Zidan, Z.H., Abdel-Megeed, M.I., Watson, W.M. and Sobeiha, A.K., 1987. Ovicidal activity of certain mineral oils, organic insecticides and their mixtures against cotton leafworm, Spodoptera littoralis (Boisd.) (Lepidoptera: Noctuidae). Appl. Ent. Zool. 22: 241-247. 